\title{
DEVELOPMENT OF COMBINED TILLAGE TOOL FOR MELON CULTIVATION
}

\author{
Nikolay Aldoshin ${ }^{1}$, Farmon Mamatov ${ }^{2}$, Ibrat Ismailov ${ }^{1}$, Gayrat Ergashov ${ }^{2}$ \\ ${ }^{1}$ Russian Timiryazev State Agrarian University, Russia; \\ ${ }^{2}$ Karshi Engineering - Economics Institute, Uzbekistan \\ naldoshin@yandex.ru,fmamatov_50@mail.ru, ismailov.ibrat85@mail.ru,ergashov.1978@gmail.com
}

\begin{abstract}
The analysis of soil processing technologies for sowing melons was carried out. When performing technological operations for sowing melons, it is necessary to perform basic and pre-sowing treatment of soil, as well as open irrigation furrows. Carrying out such operations is associated with high energy costs and multiple passes of units across the field. It is proposed to carry out strip processing of the soil for sowing melons. For its implementation, the design of a combined tillage system is proposed, which performs plowing, pre-sowing treatment and formation of irrigation furrows in one pass. When performing basic soil treatment, the plow working bodies of the front plow are used for smooth plowing, which ensures the turnover of the soil layer in its own furrow. The plow bodies of a two-body plow are installed along the axis of symmetry of the gun according to the Lister scheme. At the same time, not a complete turnover of soil layers is provided. They are simultaneously stacked in such a way that when the gun passes at their junction, an irrigation furrow is formed. Behind the plow cases, a ripping and leveling device is installed for strip pre-sowing treatment of the soil in the sowing zone. As such a working body, rotary working bodies with spherical knife elements are used, behind which a slatted roller is located. Using a combined tillage unit can reduce labor costs by up to $25 \%$, energy consumption for the process of preparing the soil by up to $50 \%$, and reduce the time of work, soil compaction and preserve moisture in the soil layer.
\end{abstract}

Keywords:soil, plowing, melon crops, plank rink, strip tillage.

\section{Introduction}

Modern agricultural production requires solving the problems of increasing crop yields, preserving and increasing soil fertility on the basis of resource-saving soil-protection technologies that provide comprehensive mechanization of all technological operations with a significant reduction in energy costs. The problem of decrease or complete exclusion of a share of manual work at performance of the most labour-consuming technological operations has a special urgency [1].

Melon crops are among the most common crops cultivated in regions with warm and hot climates. Their ability to form high yields in semi-desert environments, where the cultivation of other crops is problematic, has ensured their wide popularity. At present, melon crops are cultivated in more than 130 countries [2].

Soil treatment is an energy-intensive process. It is necessary to ensure the reduction of energy consumption and the reduction of the technological process operations. This can be achieved by creating a combined unit for cultivating soil for melon crops. Basically, melon crops are cultivated using traditional technologies and technical means to prepare the soil for sowing. This results in increased labour, time and energy consumption. Multiple passages of the units in the field result in reconsolidation of the soil. In this regard, the justification and development of combined tillage implements enabling the introduction of new and advanced technologies for preparing the soil for sowing melon crops is an urgent task.

\section{Materials and methods}

When cultivating melon crops, a number of operations are performed in a certain sequence. All operations to prepare the soil for sowing melon crops are carried out in continuous cultivation of the field. Studying the features of cultivation of melon crops, it can be noted that continuous cultivation of the field is not necessary. By cultivating the whole field, we need a lot of work and energy. In order to reduce the costs and energy it is proposed to perform a strip treatment of the field. In this case, we do not violate the technological requirements for the cultivation of melon crops. Strip cultivation should be carried out in the zone of the crop rows and the formation of irrigation furrows between them.

The following technological operations should be carried out in order to perform the full set of works on soil preparation:

- ploughing to a depth of $22-27 \mathrm{~cm}$;

- pre-sowing soil tillage; 
- formation of irrigation furrows [3].

To reduce the energy consumption for the main tillage and formation of the irrigation furrows we will give these operations with one technological method. For this purpose we use hulls of the front plough located according to the sheet scheme, i.e. symmetrically relative to the axis of the implement at the turn of the layers from the middle to the periphery [4].

Rotation of layers at frontal ploughing is shown in Figure 1.
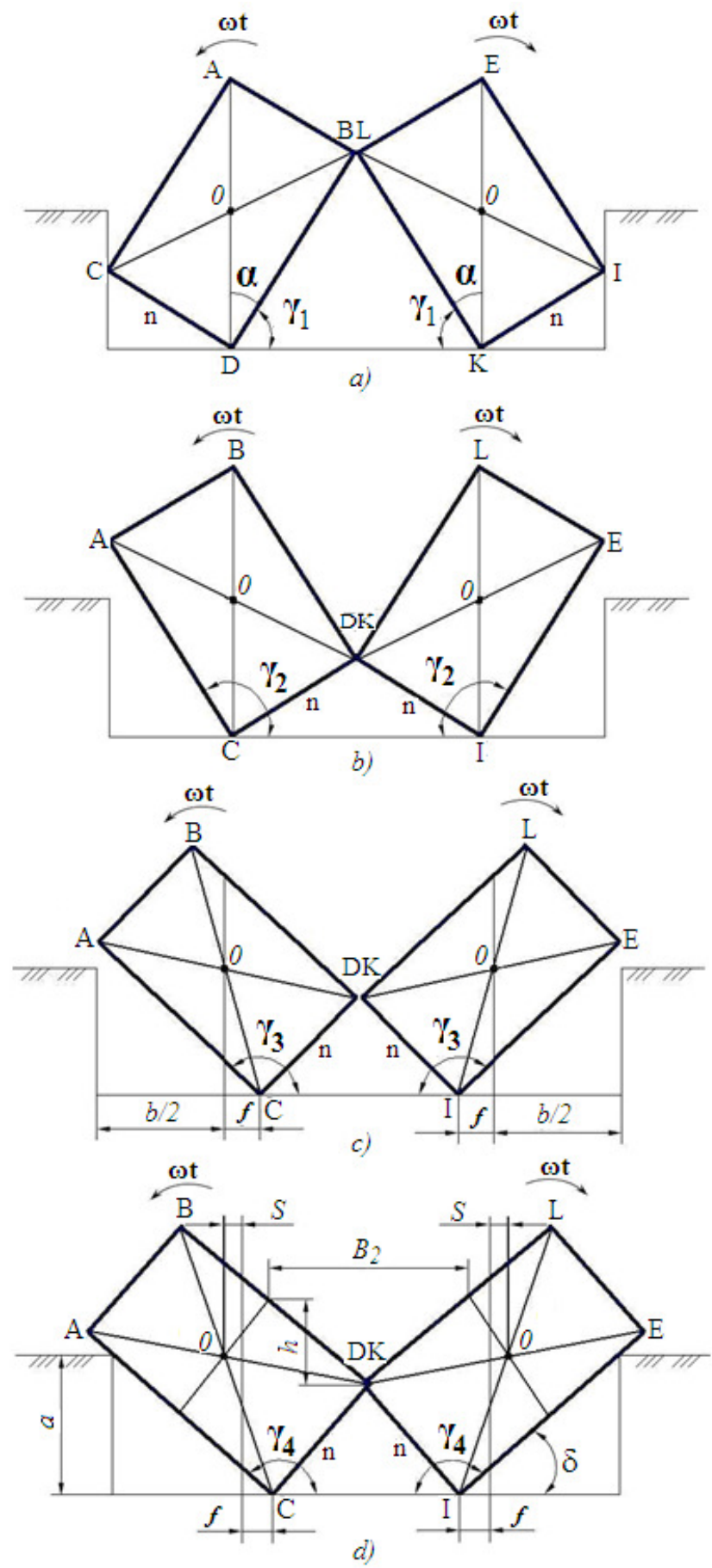

Fig. 1. Scheme of formation turnover

For a full tank rotation, a two-way impact on the tank is necessary, both on the side of the plough body and behind the plough. It is suggested not to use plungers. In this case, the turnover of layers will not be complete[5-8]. As a result, in the middle of the cultivated strip of soil naturally formed a crumbling furrow, which can be used as irrigation. The work of such a unit is shown in Figure 2. 


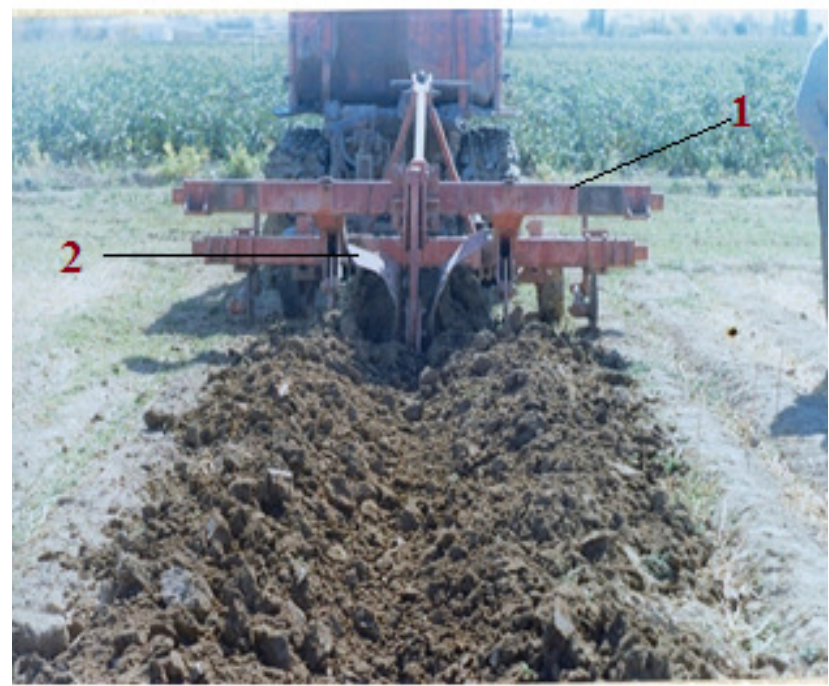

Fig. 2. Operation of the ploughing unit with front housings arranged in a sheet pattern without plungers: 1 - frame; 2 - front plough bodies

The measurement and results of the profile parameters of the field strip being processed are shown in Figure 3. During the main tillage at the depth of $22-27 \mathrm{~cm}$ it is necessary to form a field furrow $20-25 \mathrm{~cm}$ deep.

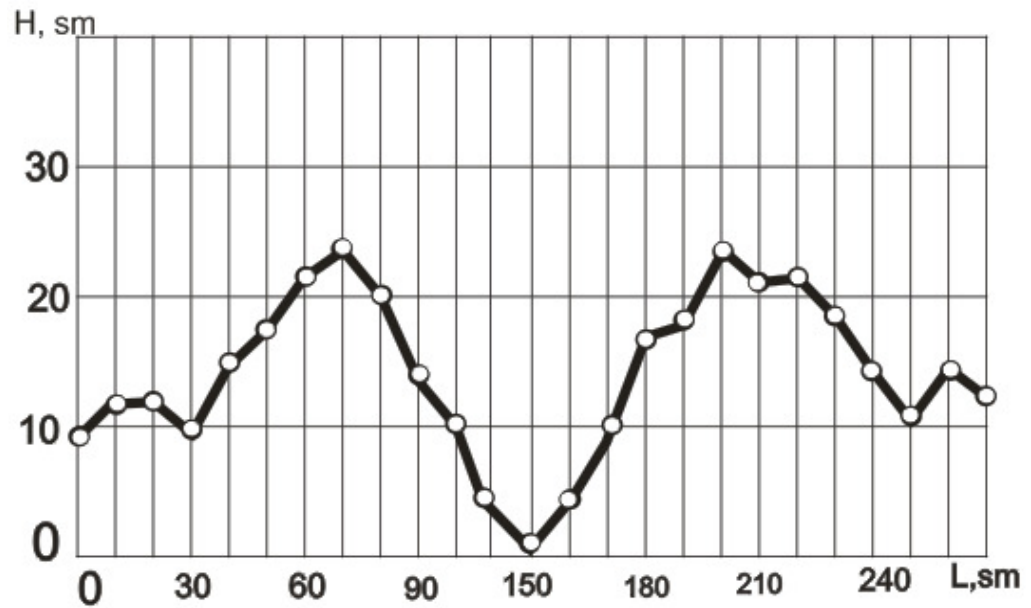

Fig. 3. Parameters of the cultivated strip of soil after ploughing

( $\mathrm{H}$ and $\mathrm{L}-$ respectively furrow profile width and height, $\mathrm{cm}$ )

As a part of the combined soil tillage unit for seedbed tillage it is proposed to use rotary working bodies with spherical knife elements. For effective operation of such a working body it is necessary to justify its structural and technological parameters. Their choice cannot be made arbitrarily, as there are rational limits to their variation, and the geometric elements of the construction are linked to each other by functional relationship.

At the present stage, disc tillage machines use solid or cut discs with constant curvature of their surface. Working elements with variable curvature are not usually used. For this reason, we also use knife elements with constant curvature of the blades. The cutting attachment is mounted with a zero angle of attack. In order to increase the surface of the blade, the blade elements are mounted on the disk with the curvature alternately directed in different directions from the plane of their attachment. Sharpening of blades is performed from the outer and inner sides of the knife elements. Recommended blade sharpening angle $i=15 \ldots 20^{\circ}$. The thickness of the blade elements can be determined by the following empirical dependence $[9 ; 10]$ :

$$
\delta=0.008 D,
$$

where $D$-diameter of the impeller, $\mathrm{mm}$. 
The results of interaction of a working body with soil depend on the size and curvature of the knife elements, working speed of the unit and the properties of the cultivated medium. The diameter of the rotary cultivator in many ways determines the quality of the operation. Excessive increase in its size is undesirable, as the vertical fold of soil resistance, which tries to push the implement out of the soil, increases. Depending on the working conditions, the smallest diameter should be selected from the permissible values, because as the diameter of the rotary cultivator increases, the load required for burial of the implement increases dramatically. The diameter therefore depends on the working depth and can be determined as follows:

$$
D=k a,
$$

where $k$-coefficient equal to (4-6);

$a$ - processing depth, cm.

Soil crumbling during cultivation is largely determined by the curvature of the knife cultivators. The greater the curvature of the knife, the more intensive the soil crumbling during cultivation. However, its radius of curvature depends on the diameter of the implement, the angle of the blade sharpening and the working depth. The diameter and radius of curvature of the blade are interrelated parameters. Depending on the diameter, the radius of curvature of the knife element can be determined by the expression[11;12]:

$$
R=\frac{D}{2 \sin \varphi},
$$

where $2 \varphi-$ angle at the sector apex, Figure 4 .

Half of the central corner of the spherical sector $\varphi$ for tillage ravines is $-\varphi=26-32^{\circ}$, disk harrows $-\varphi=22-26^{\circ}$. The radius of curvature of the knife element is a constant value. Let us assume its value in our case is equal to $26^{\circ}$.

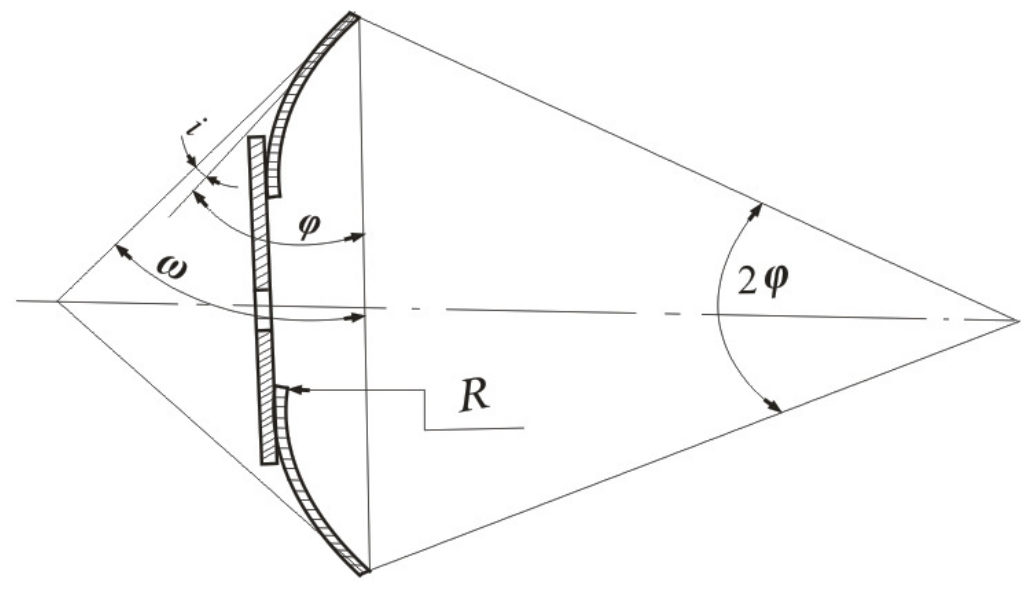

Fig. 4. Geometric dimensions in the equatorial cross-section of the spherical knife work pieces

\section{Results and discussion}

The basic geometrical parameters of a spherical knife working device include its diameter, radius of curvature, half angle at the top of the disk sector. Additionally, the corner of a sharpening cone $\omega$ and a sharpening angle $i$. We define them in the following way. In terms of expression (2) for $k=5$ and working depth of $8 \mathrm{~cm}$, we have the diameter of the blade working device equal to $400 \mathrm{~mm}$. From dependence (3) the radius of curvature of the knife element makes $455 \mathrm{~mm}$. The thickness of the knife element by the formula (1) is equal to $3,2 \mathrm{~mm}$. Taking into account the reserve of strength, we accept $\delta=4 \mathrm{~mm}$. The width of the knife element from the conditions of its strength is $40 \mathrm{~mm}$.

In connection with the installation of knife elements on the disc, alternately directed curvature in different directions from the plane of their attachment to the flange, the width of the working device will be $10 \mathrm{~cm}$. On the flange of the working device, it is possible to place 12-knives elements, given their geometric dimensions and mounting. In this case, 6 of them will be curvature in different directions, Figure5. 


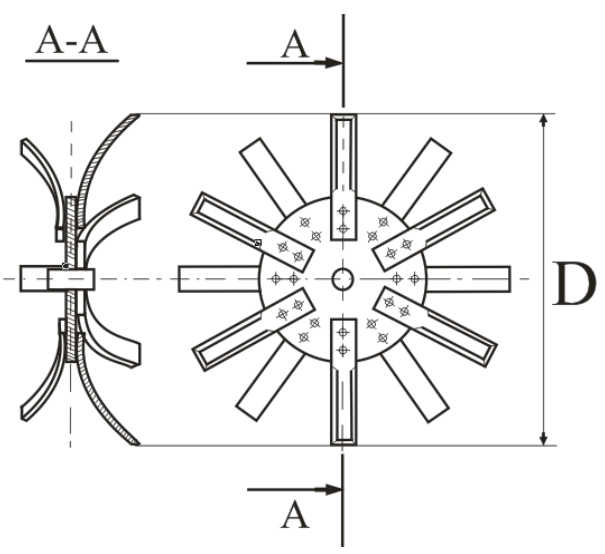

Fig. 5. Rotary soil tillage implement with spherical blade elements

If it is necessary to perform strip tillage in $30 \mathrm{~cm}$ wide seeding area, the three such rotary cultivators must be combined into batteries.

For simultaneous levelling and compaction of the soil in the sowing area, a plank roller is installed behind the rotary cultivators. In this case, the complete formation of the profile of the cultivated strip of soil and its cultivation are completed.

Combined soil cultivating unit provides in the sowing zone of melon crops at a depth of $0-10 \mathrm{~cm}$ the presence of soil fractions of $25 \mathrm{~mm}$ size of at least $80 \%$ and soil density in the sowing zone of 1.1 to $1.2 \mathrm{~g} \cdot \mathrm{cm}^{-3}$, Figure 6 . The quality of work of the tillage unit was assessed using standard methods. The accuracy of studies at certain performance indicators is at the level of $\pm 5 \%$.

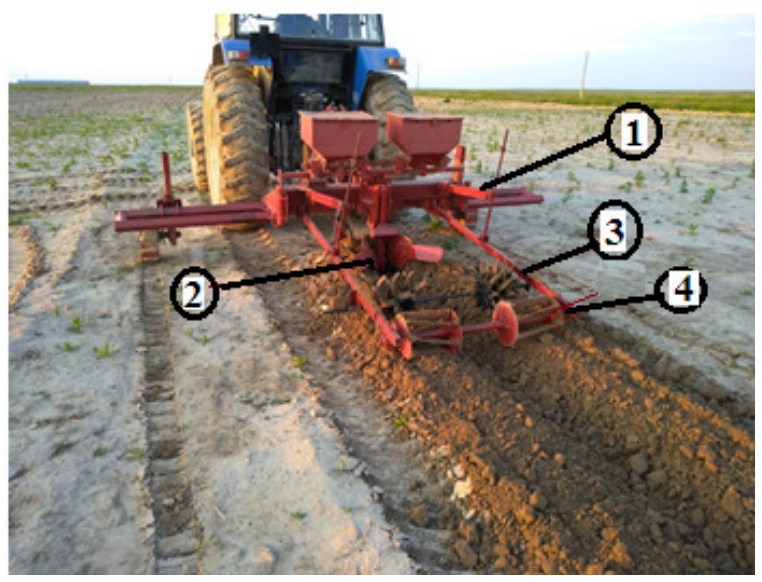

Fig. 6. Test sample of a combined tillage unit for melon crops in operation: 1 - frame; 2 - front plough bodies; 3 - rotary tillage implement with spherical knife elements; 4 - plank rink

A pilot sample of a combined tillage unit for melon crops in operation and strip tillage with formation of an irrigation furrow are shown in Figure 7, respectively.

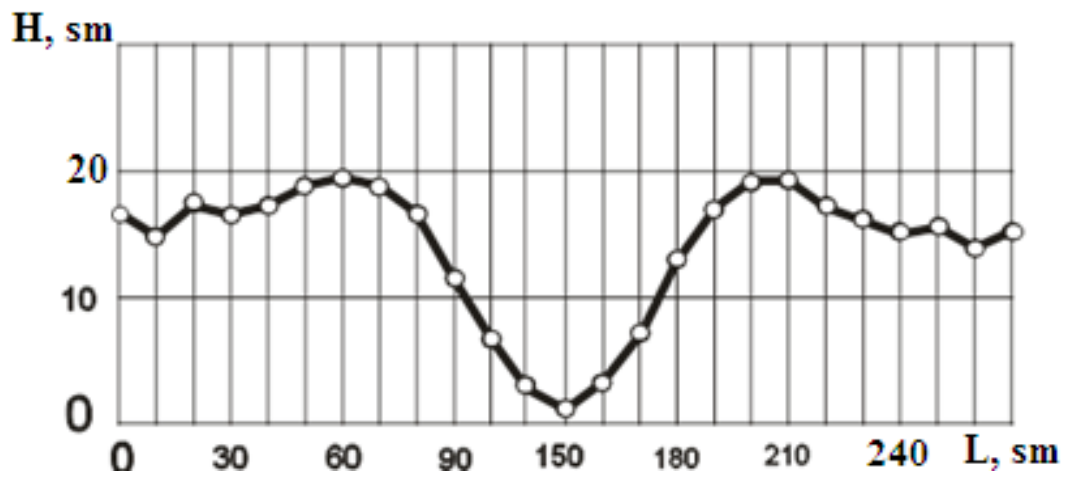

Fig. 7. Parameters of the cultivated soil strip after passing the combined machine

( $\mathrm{H}$ and $\mathrm{L}-$ respectively furrow profile width and height, $\mathrm{cm}$ ) 


\section{Conclusions}

The reduction of energy and labor costs is offset by the combined unit and the reduction of operations. Flushing is carried out with incomplete formation turnover, which results in lower energy consumption. Irrigation furrows are formed spontaneously, due to the use of the original type of ploughing. The use of the combined soil tillage unit for strip tillage when sowing melon crops allows to reduce the labor and energy costs up to $25 \%$ and $50 \%$ respectively, while reducing the time of work, preserving moisture in the soil, protecting the surface of the field from compaction by reducing the number of passes of the unit and ensuring the quality of technological operations.

\section{References}

[1] Litvinov S.S., Bykovskiy Yu.A. Bakchevodstvo: strategy and prospects of development Potatoes and vegetables. Moscow: 2013. pp. 2-6. (In Russian)

[2] Ashworth S. Seed to Seed: Seed Saving and Growing Techniques for the Vegetable Gardener. Chelsea Green Publishing, 2019. 97 p.

[3] Sarauskis E., Buragiene S., Romaneckas K., Sakalauskas A., Jasinskas A., Vaiciukevicius E., Karayel D. Working time, fuel consumption and economic analysis of different tillage and sowing systems in Lithuania. Engineering for Rural Development 2012, 11, pp. 52-59.

[4] Lobachevskiy Ya.P. Development of technological bases for creation of frontal ploughs for smooth ploughing: Cand. Cand.of Sci. (Techn.) Moscow: Dissertation, 1987. 245 p. (In Russian)

[5] Mamatov F.M. Mechanical and technological substantiations of technical means for the main soil tillage in the cotton-growing zones. Moscow: Cand. Dr. Sci. (Techn.), 1992. 33 p. (In Russian)

[6] Starovoytov V., Starovoytova O., Aldoshin N., Manohina A.. Jerusalem artichoke as a means of fields conservation. Acta Technologica Agriculturae 1. Nitra: Slovaca Universitas Agriculturae Nitriae, 2017, pp. 7-10.

[7] Zolotaryov S.A. Justification of the technological process and parameters of a plough for a smooth ploughing Moscow: Cand of Technical Sciences, 2005. $225 \mathrm{p}$.

[8] Sharov V.V. Justification of the main parameters of a rotary plough for smooth ploughing. Moscow: Cand. Sci. (Techn.) Dissertation, 1986. 227 p.

[9] Mirzaev B., Mamatov F., Aldoshin N., Amonov M. Anti-erosion two-stage tillage by ripper. Prague: Proceeding of 7th International Conference on Trends in Agricultural Engineering Czech University of Life Sciences Prague - Faculty of Engineeringp, 2019. pp. 391-395.

[10] Sineokov G.N., Panov I.M. Theory and calculation of tillage machines. Moscow: Mechanical Engineering, 1977. 326 p.

[11]Lal R., Shukla M.K. Principles of Soil Physics, Marcel Dekker Inc.: New York, NY, USA, Basel, Switzerland, 2004.

[12]Romaneckas K., Avižienyte D., Bogužas V., Šarauskis E., Jasinskas A., Marks M. Impact of tillage systems on chemical, biochemical and biological composition of soil. J. Elem. 2016, 21, pp. 513-526. 